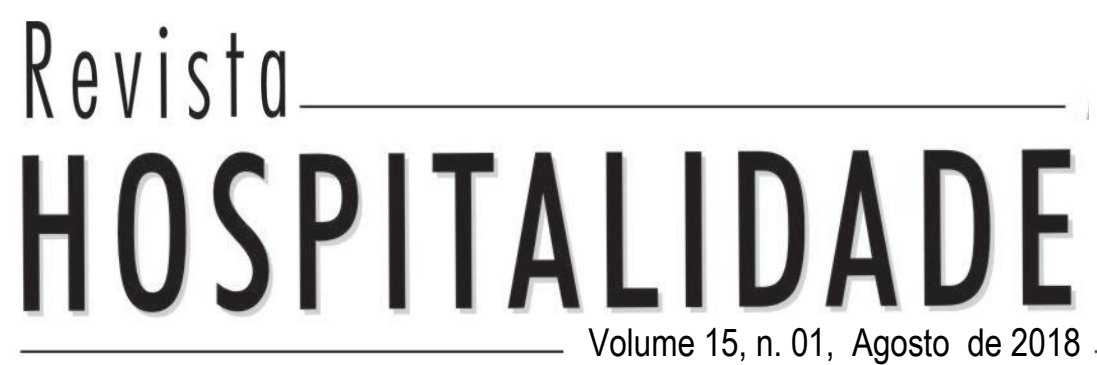

ISSN 1807-975X

\title{
USOS DAS TECNOLOGIAS DE COMUNICAÇÃO NOS MEIOS DE HOSPEDAGEM E AGÊNCIAS DO MUNICIPIO DE PARNAIBA/PIAUÍ/BRASIL
}

\section{THE USE OF COMMUNICATION TECHNOLOGIES IN TOURISM COMPANIES IN THE CITY OF PARNAÍBA/PIAUÍ/BRAZIL}

\begin{abstract}
RESUMO
O presente artigo tem como objetivo identificar como são utilizadas as ferramentas de tecnologias de informação e comunicação (TIC's) nas empresas turísticas do município de Parnaíba- Piauí. Por se tratar da cidade que abriga o Delta do Parnaíba e por ser uma região constituída de outros atrativos turísticos como, a praia da Pedra do Sal e o Centro Histórico Porto das Barcas, se faz relevante diagnosticar como têm sido utilizadas estas ferramentas para promover o destino e a economia local desta cidade. Como procedimentos metodológicos optou-se pela pesquisa de campo com questionários aplicados junto aos empresários, além de formulários utilizando a mineração de conteúdo na internet. Os resultados demostram que o Facebook, Instagram e Sites são os meios de comunicação mais utilizados, no entanto são poucas as empresas que fazem o uso devido dessas mídias sociais, apesar de a maioria possuir perfil nas mídias sociais.
\end{abstract}

Palavras-chave: Marketing Turístico; Redes Sociais; TICs

\begin{abstract}
This article aims to identify how information and communications technology (ICT) tools are used in tourism companies in the city of Parnaíba-Piauí. Due to the fact that the Delta of the Parnaíba is in the city, and its surrounding area hosts other touristic attractions, such as the Pedra do Sal beach and the Historical Center at Porto das Barcas, it is relevant to diagnose how technology tools have been used to promote the destination and the local economy of the city. The methodology was comprised of field research with questionnaires to the businesses owners, as well as forms using content mining on the Internet. Results show that Facebook, Instagram and websites are the most used means of communication; however, few companies use such social media, even though the majority have a profile in them.
\end{abstract}

Key words: Touristic Marketing; Social Network; Information and Communications Technology

\section{INTRODUÇÃO}

O município de Parnaíba está localizado no extremo Norte do Estado do Piauí/Brasil, é banhado pelo Rio Igaraçu e pelo Oceano Atlântico, possui uma área populacional de 434,229 $\mathrm{km}^{2}$, uma população de 150.201 habitantes e densidade demográfica de 344,84 hab./km² , IBGE (2016). Tem como limites, ao Norte Oceano Atlântico, ao Sul Buriti dos Lopes, ao Leste Luís Correia e a Oeste Ilha Grande do Piauí. Distância de 339km da capital, Teresina (PARNAÍBA, 2016).

\footnotetext{
${ }^{1}$ Bacharel em Turismo (UNIMEP); Especialista em Docência em Ensino Superior para Turismo e Hotelaria (SENAC/SP); Mestre em Geografia (UNESP/Rio Claro/SP) e Doutor em Ciências da Comunicação (UNISINOS). Professor Adjunto, D.E, EFETIVO, da Universidade Federal do Piauí - Curso de Bacharelado em Turismo - CMRV/Parnaíba-PI e Professor Permanente do Mestrado em Gestão de Negócios Turísticos da UECE. E-mail: perinotto@ufpi.edu.br

${ }^{2}$ Bacharel em Turismo pela Universidade Federal do Piauí, Ex-aluna de Iniciação Científica UFPI. E-mail: adyelleveras@hotmail.com

${ }^{3}$ Bacharel em Turismo pela Universidade Federal do Piauí, Ex-aluna de Iniciação Científica pelo CNPq. E-mail: thaianetorres7@ gmail.com

${ }^{4}$ Bacharel em Turismo pela Universidade Federal do Piaú, Ex-aluna de Iniciação Científica pelo CNPq. E-mail: leticiamariabarbosa93@gmail.com
} 
A cidade acolhe diversos atrativos naturais, com destaques para o delta do Rio Parnaíba - um ecossistema formado por dunas, mangues e rios; a Lagoa do Portinho e a Praia da Pedra do Sal, formada por imensas rochas que invadem o mar (PIAUÍ, 2015).

A propósito, são vários os aspectos culturais que atraem a curiosidade do visitante, a exemplo da gastronomia à base de peixes, frutos do mar e doces caseiros, as danças populares, o artesanato de fibras e madeira ou as expressões plásticas dos artistas locais atraem os que passam por lá (PIAUÍ, 2015). De fato, para uma cidade receber visitantes precisa ser divulgada e é através dos mecanismos da comunicação e do marketing que isto se tornará possível. Com a globalização, a era da internet, as pessoas obtêm mais informações facilitando assim a intermediação dos prestadores de serviços com seus clientes. Neste sentido, seguindo o pensamento de Buhalis (1998 apud Da Silva Flores et al. 2012, p.323-324):

As Tecnologias de Informação (TI) prevalecem em todas as funções de gestão estratégica e operacional e, sendo a informação elemento primordial para o turismo, as TI proporcionam então oportunidades e desafios para o setor. Por isso, cada vez mais as organizações e os destinos estão sendo forçados a usarem as emergentes ferramentas de TI para melhoria da sua competitividade.

No turismo, por exemplo, a internet e suas ferramentas têm contribuído para um melhor relacionamento entre empresa e clientes, ao proporcionarem divulgação, incentivo e promoção de atrativos ou potenciais atrativos. Desta maneira "os meios de comunicação são um instrumento que, uma vez bem utilizado, pode levar as entidades públicas do turismo e o sector privado a atingir os seus objetivos promocionais: divulgar, motivar e causar impacto" (MARUJO, 2008, p.11).

A partir disso, fez-se necessária a realização de uma pesquisa junto às empresas de turismo do município de Parnaíba e na Internet para identificar como as empresas fazem usos dessas ferramentas e das redes sociais para divulgação de seus produtos e serviços. A pesquisa identificou como as tecnologias de comunicação estão sendo utilizadas nas empresas turísticas do município, avaliou a relevância da Tecnologia de Comunicação no marketing empresarial, através da percepção dos responsáveis por essas empresas turísticas e também analisou como é feito este uso de fato na Internet.

Diante do exposto, este trabalho apresenta a internet e as redes sociais como meios de comunicação no turismo e a importância das empresas atentarem-se para as novas tendências, 
ao passo que o turismo está em constante mudança, áreas relevantes para o desenvolvimento do turismo em uma localidade para a promoção e a divulgação de seus produtos e/ou serviços.

\section{MARKETING DIGITAL NO TURISMO}

No turismo é importante destacar que a base das motivações do turista é a necessidade e, para que seja despertada é preciso de algo que a estimule, como por exemplo, o marketing, que se direcionará para as necessidades do ser humano e as tornarão possíveis de se concretizarem. Nesse sentindo, Perinotto (2013, p.34) “verifica-se que a mídia será um espaço fundamental para construção das identidades regionais nacionais com posicionamento turístico e também para que estas sejam percebidas pelo turista como tal", o que a torna um meio relevante de divulgação de seus destinos e promoções, seja pela televisão, jornal ou mídias sociais.

Desse modo, Arruda e Pimenta (2005, p.52) afirmam que o uso das TICs "tem um papel de extrema importância ao diminuir sensivelmente o espaço físico para a transmissão de informações e produção do conhecimento". Por sua vez, De Sena Jardim e Sant' Anna (2008, p.02) apontam o fato de que:

As tecnologias da informação e comunicação - TIC's -, por meio de seus inúmeros suportes midiáticos, como o jornal, a televisão e o rádio, rompem barreiras e promovem o acesso e a veiculação de informações a todas as formas de comunicação e em todas as partes do mundo.

Do mesmo modo, Souza e Kovacs (2009, p.204) caracterizam o marketing como "uma das principais ferramentas utilizadas pelas empresas e organizações para lidar com seus clientes. Seus efeitos podem ser percebidos diariamente, por várias pessoas, em diferentes partes do planeta”. Dentro desta perspectiva, observa-se que as pessoas estão cada vez mais conectadas e com isso há a necessidade das empresas adaptarem-se e utilizarem o comércio virtual para dispor de um melhor relacionamento com seus clientes e/ou também, atrair cada vez mais potencias clientes.

Hoje, a Internet possibilita ao turista acesso a informações amplas sobre seu objeto de turismo. Dessa forma, suas ações são cada vez mais direcionadas pela quantidade e qualidade das informações prestadas, sejam pelas operadoras de turismo ou órgãos governamentais responsáveis pelo desenvolvimento turístico de uma região (TOMIKAWA, 2009, p.64).

Vale acrescentar que a internet se tornou o meio de distribuição de conteúdo mais utilizado seja por meio de áudios, imagens ou vídeos e é notável como tem proporcionado ao 
turista o acesso e obtenção de informações ou ainda, como descrito por Brasil (2010, p.123), "a internet é uma ferramenta de extrema importância para o processo de comercialização e divulgação de produtos turísticos".

Dentro desta linha, Cruz et al. (2012, p.7) afirmam que "a internet se tornou, portanto, um canal mais adequado na distribuição de informação através de dados, fotos, vídeos, sons, imagens virtuais e em tempo real atingindo, assim, milhões de pessoas a um baixo custo". Sendo assim, as empresas devem se adaptar e utilizar o marketing digital, isto é, investindo em campanhas online, como nas redes sociais, que além de ser um instrumento de divulgação, possui baixo custo de utilização e pode-se medir os resultados, sabendo qual o alcance de sua postagem.

A propósito, quanto ao marketing digital requer um uso adequado para que se obtenha retorno das publicidades investidas. Um exemplo atualmente é a utilização de vídeos ou Live nas redes sociais; agora o Facebook, Instagram e Youtube podem realizar transmissão ao vivo com exceção do WhatsApp que não possui a ferramenta de Live, apenas de vídeos curtos, assim as empresas podem empregá-las para promover sua marca, destino, serviço e produto. Conforme ressaltam De Sena Jardim e Sant'Anna (2008, p.3):

\footnotetext{
A internet, hoje, representa uma das principais tecnologias de informação e comunicação. Essa nova ferramenta trabalha, por meio de milhares de computadores interconectados, em diversas partes do mundo, permitindo a troca de dados e informações disponibilizados em uma ampla rede.
}

Além disso, ultimamente as empresas têm utilizado as redes sociais para promoção, divulgação e comercialização de seus produtos e/ou serviços e, como a maiorias das pessoas estão conectadas com seus smartphones, as empresas devem se adaptar e utilizar-se da internet e das redes sociais a seu favor, realizando campanhas publicitárias, divulgando seus produtos ou serviços. Portanto, pode-se dizer que o marketing digital é importante e que todas as empresas devem usar a internet e as mídias sociais, pois possuem grande importância na tomada de decisão e influência dos clientes. Além de que a internet possibilita um alcance maior de pessoas. 


\section{GESTÃO DE MARKETING EM EMPRESAS TURÍSTICAS}

O estudo do marketing turístico pelas empresas do setor merece ser aprofundado, devido ao fato de que as viagens não são consideradas necessidades básicas para o ser humano, de acordo com a teoria de Maslow de 1943, (KOTLER e KELLER, 2006). Seguindo o pensamento de Maslow, a viagem só estaria no $4^{\circ}$ ou $5^{\circ}$ topo da hierarquia das necessidades básicas, quando já passado pelas necessidades fisiológicas, de segurança e sociais, partindo então para as últimas necessidades de estima e de auto realização, lembrando que essa última é inalcançável, pois sempre se deseja mais, um ciclo sem fim.

Conforme ressalta Cobra (2009) o consumidor é a chave de sucesso para o mercado, porque para praticar o marketing precisa entender como funciona a mente do consumidor, como ele faz suas escolhas no momento decisório da compra. Ainda segundo Cobra (2009, p.89) "o fluxo da informação de mudanças tecnológicas, ou de surgimento de novas gerações de produtos decorrentes de avanços de automação, que reduzam custos, pode levar as pessoas à busca de compra." A redução de custos pode ser sentida tanto pelo consumidor como pelo empresário, pois com a tecnologia avançada as divulgações tornaram-se mais eficazes, com um custo menor e mais rápido, e o consumidor recebe todas as informações sem ter a obrigação de deslocar-se de sua casa. Por conseguinte, o autor ressalta também a ideia de que:

O setor serviços está entre aqueles que mais têm se beneficiado com toda essa mudança. Atualmente podemos realizar uma série de operações financeiras em todo o mundo, comprar passagens aéreas, reservar hotéis e um sem-número de operações sem que seja necessário sair de nossas casas (COBRA, 2009, p.393).

No turismo aborda-se o marketing turístico em etapas comuns do marketing geral como a fidelização do cliente, pesquisa de demanda, além da tecnologia voltando-se mais para as mídias sociais e sua relação com o consumidor. Ao ligar-se com a administração de marketing no geral deve-se ter uma noção básica do que se quer propor em suas etapas e lembrar que marketing não é só propaganda ou promoção, mas a fidelização do produto ou do serviço no mercado, já que com a era da informática e da internet compete com todos os similares no mundo. Dessa forma, Kotler e Keller (2006, p.4) abordam que "o marketing envolve a identificação e a satisfação das necessidades humanas e sociais. Para defini-lo de uma maneira bem simples, podemos dizer que ele "supre necessidades lucrativamente"'.

No marketing turístico um dos enfoques pontuados são a promoção de produtos/serviços e as informações contidas na divulgação de um destino deve ser relevante, 
devido ao fato de que o produto turístico é intangível. Diferente de outros produtos, ele não pode ser tocado ou experimentado antes de sua compra e, para que haja uma venda satisfatória é imprescindível a disposição de informações detalhadas, pois o produto é uma experiência, uma viagem, uma memória, que pode gerar um retorno positivo ou negativo, tanto para as empresas quanto para os destinos. Dessa forma, faz-se necessário que a empresa prestadora de um determinado serviço se atente para que as informações contidas no pacote/serviço sejam verdadeiras e o cliente obtenha a satisfação após o serviço prestado. Assim, Rushmann (1990, p.113):

Como já ressaltamos, na atividade turística o indivíduo compra uma experiência intangível e impossível de ser avaliada antes de efetivamente vivida. Portanto, a credibilidade das mensagens enviadas por meio da propaganda e das promoções é um aspecto fundamental da sua comercialização. (RUSHMANN, 1990, p.113)

Logo, para que as empresas tenham um resultado positivo das divulgações e promoções do destino, é imprescindível ter credibilidade com os subsídios postados nos meios de comunicação para que o desejo do consumidor seja alcançado. Para isso, é indispensável ter um site esteticamente atraente, que atraia olhares, conhecimento do seu público alvo para que qualquer mudança não acabe sendo desnecessária, ou posta em prática em momento inoportuno.

Com relação as redes sociais, no Instagram é preciso estar atento qual o melhor horário para realizar o post para alcançar um número maior de espectadores e curtidas, e também na utilização das hashtags. Para conquistar a atenção do consumidor à página da empresa é preciso focar no que vai postar, pois é nisso que o consumidor pode-se mostrar interessado na sua empresa e manter-se atualizado com as suas postagens. É recomendado que se utilize de ferramentas como o Google Analytics para uma precisão de dados e um monitoramento de sua rede social e suas postagens. Borges (2016) apresenta um conceito simples e prático sobre a ferramenta ao afirmar que o Google Analytics é:

É a ferramenta que o Google disponibiliza para avaliar a performance dos sites, blogs e redes sociais e campanhas pagas. Com ela você identifica de onde vêm seus visitantes, quais as palavras-chave mais digitadas pelos internautas, quais as páginas mais acessadas no seu site/blog, taxa de rejeição, rendimento dos seus anúncios no Google, dentre outras métricas.

Quanto à escolha da mídia ou seu canal de comunicação com o consumidor, Cobra (2009, p.395) afirma que: 


\begin{abstract}
Atualmente, as pessoas podem ler jornais, assistir a programas de televisão, escutar a sua rádio de preferência através da Internet. Esse veículo tem conseguido aglutinar todas as outras formas de comunicação e prender os seus usuários apenas na utilização da Internet. Essa é uma informação que deve ser levada em consideração na hora da escolha do canal de comunicação que as empresas irão utilizar para vincular as suas campanhas de marketing. (COBRA, 2009, p.395)
\end{abstract}

No Brasil, é perceptível que após a revolução da informação a maioria dos canais de comunicação é feita pela internet e, com o aumento do seu alcance, sua rápida divulgação e seu baixo custo contribui para a disseminação e utilização por todas as camadas sociais e regiões. Logo, se determinada pesquisa apontar que a maior parte dos consumidores está conectada à internet por meio de mídias sociais torna-se um fator relevante para que a empresa disponha seus produtos, o que remete a seguinte argumentação de Borges (2013):

Muitos empresários e gestores turísticos ainda acham que as redes sociais é "brincadeira". Mas elas representam um canal relevante para viabilizar o relacionamento da empresa com o público-alvo. É fundamental utilizá-las de forma estratégica, criando engajamento com fãs e curtidores. (BORGES, 2013, s/p.)

Portanto, as redes sociais demonstram nos últimos anos uma abrangência em divulgação e promoção de produtos, além de um site que ajuda na pesquisa de consumidores através das ferramentas que a mídia social disponibiliza ao cadastro do usuário com seções como esportes preferidos, time preferido, filmes preferidos, músicas preferidas, assim é possível montar um perfil de consumidor com apensar algumas informações que estão disponíveis no perfil do usuário nesta mídia social.

\title{
METODOLOGIA
}

A pesquisa teve como objetivo, averiguar como as empresas turísticas do município de Parnaíba/Piauí estão utilizando os meios de comunicação como suporte para divulgação e atração de turistas para a localidade. Para atingir esses objetivos propostos foi utilizado dois métodos, o primeiro foi a utilização do questionário, com abordagem quantitativa, contendo 20 questões semiestruturadas, aplicados diretamente com os sujeitos responsáveis pelas empresas turísticas do município de Parnaíba, sendo disponibilizado o questionário impresso e online pela plataforma do GoogleDocs, e o segundo método foi a pesquisa online, através de formulários, realizando análise nos próprios meios de comunicação que as empresas afirmaram utilizar anteriormente nos questionários. Sendo assim, para Baptista e Cunha (2007, p. 177), 
questionário "é um dos métodos mais utilizados. Consiste numa lista de questões formuladas pelo pesquisador a serem respondidas pelos sujeitos pesquisados”. Já Cervo e Bervian (2002, p.48) afirmam que o questionário "[...] refere-se a um meio de obter respostas às questões por uma fórmula que o próprio informante preenche”. Sendo assim o questionário é importante para obtenção de respostas sobre determinado assunto a ser pesquisado, bem como a pesquisa na Internet para a constatação do que foi afirmado sobre o uso da Internet para a promoção do destino e meios de hospedagem de Parnaíba.

Inicialmente, realizou-se estudos bibliográficos em livros, artigos científicos e conteúdo na internet sobre o tema abordado, para melhor aprofundamento e conhecimento sobre o assunto e pesquisa de campo. Em seguida, foi escolhida quais empresas fariam parte da pesquisa, sendo realizado apenas com agenciamento e hospedagem, a escolha se deu através das empresas que possuíam cadastro no CADASTUR, que é uma plataforma do Ministério do Turismo para cadastro de pessoas físicas e jurídicas que atuam na área do turismo, e empresas que fazem parte da Rota das Emoções, um roteiro integrado com os principais atrativos turísticos dos estados do Ceará, Piauí e Maranhão. Observou-se quanto a isso que a cidade possui empresas turísticas, porém nem todas possuem cadastro nessa plataforma.

Em seguida iniciou-se a elaboração dos questionários e para validá-los foi realizado o pré-teste para saber se as perguntas estavam compreensíveis bem como foi verificado o tempo de aplicação do questionário para serem feitos os ajustes posteriores aplicação de pré-teste. Sobre a importância dessa etapa inicial Marconi e Lakatos (1996) explanam que os pré-testes, devem ser realizados com o questionário numa versão quase definitiva, com capa e formatação já em seu estado final.

Em junho de 2015, período que foi realizado a pesquisa das empresas no CADASTUR foi obtido um total de 40 empresas cadastradas incluindo agências de turismo e meios de hospedagem. Sendo 19 de agenciamento e 21 meios de hospedagem. Entretanto, não foi possível aplicar o questionário com todos, tendo em vista que algumas empresas não mantinham seus dados atualizados na plataforma, verificou-se que os e-mails e telefones cadastrados não eram utilizados e assim dificultando a comunicação no processo de coleta de dados. logo no início da pesquisa foi possível perceber erros quanto ao uso das tecnologias da comunicação, já que o e-mail e o telefone são uma das principais ferramentas de comunicação usadas pelas empresas para a obtenção de informações e contato para cliente e fornecedor. 
As saídas a campo para aplicação dos questionários foram realizadas nos meses de novembro e dezembro de 2015 e outubro de 2016, em 22 empresas turísticas do município de Parnaíba-PI. A coleta dos dados se deu por meios dos questionários impresso e eletrônicos.

No total foram aplicados em mais de 50\% (22 empresas) dos questionários, considerando uma quantidade satisfatória. Os dados coletados dos questionários foram tabulados na plataforma do Excel utilizando a tabela dinâmica e desenvolvendo as tabelas para análise dos resultados. Sendo assim Battisti e Battisti (2008) afirma que "Usando uma planilha eletrônica podemos manipular com facilidade a edição de tabelas, efetuar cálculos, operações estatísticas e a geração de gráficos. De forma geral permite armazenar dados e produzir informações a partir destes".

Após a obtenção destes resultados provenientes do questionário, buscou-se complementar a análise dos dados ao distinguir o uso efetivo das Tecnologias da Informação e Comunicação através da Internet, já que o questionário traz apenas a visão do empresário, tevese o interesse de investigar se o que foi afirmado no questionário condiz com a realidade. Para tal fim utilizou-se formulários estruturados de análise baseado nos elaborados por Thomaz (2011) e Thomaz (2014) em sua pesquisa sobre mineração de dados, no entanto com adaptações que possibilitaram a busca de informações sobre como se dá a presença dessas empresas na web. O formulário continha questões de análise sobre como as empresas utilizam cada ferramenta disponível no meio de comunicação, o período de uma postagem e outra, a quantidade de likes nas postagens e os tipos de postagem.

Sendo assim, os formulários constituem a última etapa da pesquisa, em que foram utilizados formulários para os sites, para as fanpages e para o Instagram das empresas em questão, foi feito o monitoramento desses meios de comunicação durante todo o tempo da pesquisa, com intuito de analisar o engajamento das empresas nas mídias sociais, Thomaz (2014 p.70) explica a importância de monitorar as mídias sociais "O monitoramento em mídias sociais é uma estratégia emergente que tem como objetivo extrair informações relevantes de conteúdos não estruturados e oferece diversas oportunidades, vantagens e benefícios as organizações para adquirir vantagem competitiva". Para o levantamento desses dados foi feito no período compreendido entre novembro de 2016 a julho de 2017 a imersão na internet para se vasculhar o conteúdo presente nos sites próprios das empresas, Facebook (fanpages) e 
Instagram, os formulários foram adaptados para cada um desses locais na web que dizem respeito as empresas do Litoral do Piauí.

\section{RESULTADOS E DISCUSSÕES}

\section{Análise dos questionários}

Depois realizado a pesquisa de tecnologia de informação e comunicação com as 22 empresas turísticas (agenciamento e hospedagem) do município de Parnaíba-PI foi possível diagnosticar que predomina o uso das redes sociais nas empresas e como as empresas utilizam para atração e divulgação de seus serviços.

Com relação às redes sociais ou página da web se as empresas possuem perfil (Tabela 1) foi constatado que a rede social mais utilizada é o Facebook (31,67\%). Devido ao fato de conseguir divulgar a empresa, os atrativos e serviços, além de o Facebook oferecer uma plataforma que pode interagir com vários usuários de todo o mundo com baixo custo, facilitando a comunicação entre empresas e usuários, seguindo pelo Site (28,33\%) e Instagram (23,33\%). Nesse sentido Cruz et al.2012, p.8) afirmam que “As Redes Sociais são uma oportunidade para quem deseja divulgar seu produto ou marca e fidelizar possíveis clientes, já que ultrapassaram os números de acessos aos e-mails e continuam crescendo em quantidade de acesso", sendo assim é importante que as empresas que atuam no turismo se adaptem a essas novas formas de tecnologias.

Sendo assim, segundo Da Silva Costa e Perinotto (2017, p.12) afirmam que "Apenas as agências A, B, J, M, P e Q fizeram atualizações em seus perfis. No total de 14 publicações divididas entre informativos, divulgação de Parnaíba e região local, promoções e pacotes, destinos turísticos e outros." De 16 agências apenas 6 no período de uma semana em que foi feita a observação realizou publicação no Instagram, demostrando desinteresse por parte de algumas empresas que não mantem suas redes sociais atualizadas, sabendo que elas são uma ponte entre o cliente e o fornecedor, podendo obter informações através dela, por isso a necessidade de realizar dois métodos de coleta de dados nessa pesquisa, pois algumas empresas possuem rede sociais, mas não as utilizam de fato. 
Tabela 1: Perfil em Redes Sociais

\begin{tabular}{lc}
\hline Perfil em redes sociais e página da web & Incidência \\
\hline Facebook & $31,67 \%$ \\
Instagram & $23,33 \%$ \\
Twitter & $3,33 \%$ \\
Google+ & $10,00 \%$ \\
Site & $28,33 \%$ \\
Blog & $1,67 \%$ \\
Outros & $1,67 \%$ \\
Total & $\mathbf{1 0 0 , 0 0 \%}$ \\
\hline
\end{tabular}

Fonte: Pesquisa Direta (2017).

Em relação às quais sites de viagens a empresa estava cadastrada (Tabela 2) foi visto que Booking e Decolar (ambos com 25\%) a maioria das empresas entrevistadas estão cadastradas em pelo menos algum site de viagem. O turista para se deslocar, precisa de informações e é através dos sites, mídias sociais e da internet que ele irá adquirir essas informações. Seguindo o pensamento De Andrade (2012, p.5) "A internet, portanto, disponibiliza uma grande variedade de informações às quais o indivíduo pode ter acesso sem que seja necessário investir muito esforço, tempo ou dinheiro. Isto porque a rede virtual leva informação ao consumidor de maneira análoga ao que acontece no mundo real”. Além de que, os sites de viagens vendem mais que as plataformas comuns como telefone e e-mail, pois o turista quer um local onde ele possa escolher a melhor hospedagem sem ter que entrar em contato com todas que existe em determinado destino, e sem precisar sair de casa para realizar todo procedimento de compra.

Tabela 2: Cadastro em sites de viagens

\begin{tabular}{lc}
\hline Cadastro em sites de viagens & Incidência \\
\hline TripAdvisor & $17,86 \%$ \\
Booking & $25,00 \%$ \\
Hotel Urbano & $10,71 \%$ \\
Decolar & $25,00 \%$ \\
Expedia & $7,14 \%$ \\
Outros & $14,29 \%$ \\
Total & $\mathbf{1 0 0 , 0 0 \%}$ \\
\hline
\end{tabular}

Fonte: Pesquisa Direta (2017).

$\mathrm{Na}$ (Tabela 3) a pesquisa mostra que as empresas fazem uso de algum tipo de imagem fotográficas para divulgação, sendo apenas Paisagem $(27,27 \%)$ e seis empresas que divulgam Paisagem, Patrimônio, Infraestrutura e Gastronomia (27,27\%), a paisagem de um local fica 
como a primeira impressão, se a pessoa não se senti atraindo pela imagem, provavelmente que não despertará o interesse de ir pesquisar sobre o local. Nesse sentido Tomikawa (2004, p.25) relata que "A imagem é de importância fundamental para a preferência, a motivação e o comportamento de um indivíduo com relação a produtos e destinações turísticas, já que irá fornecer um efeito "impulso" que resultará em diferentes prognósticos de demanda". A imagem fotográfica possibilita que a informação de destinos através da imagem chegue até o turista e que tenha o contato com o local antes mesmo de visitá-lo, a imagem é capaz de influenciar e motivar o cliente a sair do seu cotidiano, por isso a imagem fotográfica precisa ser trabalhada como estratégia de marketing na comunicação para que o produto ou serviço torne-se conhecido.

Tabela 3: Imagens fotográficas para divulgação

\begin{tabular}{lcc}
\hline Imagens fotográficas para divulgação & $\begin{array}{c}\text { Frequência } \\
\text { Absoluta }\end{array}$ & $\begin{array}{c}\text { Frequência } \\
\text { Relativa (\%) }\end{array}$ \\
\hline Paisagem, Patrimônio, Infraestrutura e Gastronomia & 6 & $27,27 \%$ \\
Paisagem & 6 & $27,27 \%$ \\
Paisagem e Patrimônio & 3 & $13,64 \%$ \\
Paisagem, Infraestrutura e Gastronomia & 2 & $9,09 \%$ \\
Paisagem e Infraestrutura & 3 & $13,64 \%$ \\
Patrimônio e Infraestrutura & 1 & $4,55 \%$ \\
Nenhum & 1 & $4,55 \%$ \\
Total & $\mathbf{2 2}$ & $\mathbf{1 0 0 , 0 0 \%}$ \\
\hline
\end{tabular}

Fonte: Pesquisa Direta (2017).

Em relação ao compartilhamento de conteúdo gerado pelo usuário/consumidor, os resultados revelaram que $68,18 \%$ das empresas entrevistadas incentivam seus clientes a compartilharem conteúdos, o CGU é importante para que outro usuário possa visualizar a reputação e o que estão falando da empresa. Assim, os turistas podem ter acesso às informações que precisam e contribuir com suas experiências compartilhadas com outros usuários. Desse modo, "muitos desses sites de mídia social ajudam os consumidores a publicar e compartilhar seus comentários, opiniões e experiências pessoais relacionados a viagens, que então servem de informações para outros” Xiang e Gretzel (2010, p.1).

Pelo motivo do produto turístico ser intangível, as pessoas procuram comentários, opiniões de outras pessoas que já vivenciaram a experiência, melhorar obtenção de informações, e para tomada de decisão. Ainda segundo Leung et al $(2013$, p.8) "CGU nas mídias sociais é capaz de fornecer formatos de informação sem precedentes atualizados e 
diversificados para viajar aos consumidores". O compartilhamento de conteúdo pelos usuários tem incentivado os viajantes na tomada de decisões. E em Parnaíba 37,04\% das empresas utilizam CGU através das fotografias, logo em seguida as hashtags $25.93 \%$. Desse modo Da Silva e Mendes Filho (2014, p.10) relatam que "os usuários, além de utilizarem a internet para obter informações sobre localidades, se envolvem para trocar informações sobre experiências passadas sobre produto e/ou serviço" assim pode-se considerar o CGU como uma comunicação boca a boca virtual, conforme apresentam Gretzel e Yoo (2008). Com o uso da Internet o planejamento de viagens tornou-se cada vez mais prevalente, a tomada de decisões de viagem espera-se que os processos se tornem cada vez mais influenciados pelo boca-a-boca eletrônico.

Tabela 4: Compartilhamento de CGU

\begin{tabular}{lc}
\hline Compartilhamento de CGU & Incidência \\
\hline Avaliações & $18,52 \%$ \\
Fotografias & $37,04 \%$ \\
Vídeos & $18,52 \%$ \\
Hashtags & $25,93 \%$ \\
Total & $\mathbf{1 0 0 , 0 0 \%}$ \\
\hline
\end{tabular}

Fonte: Pesquisa Direta (2017).

Em relação às hashtags as empresas do município de Parnaíba-PI 50\% utilizam no Facebook e 31,82\% Instagram. As hashtags são palavras precedidas com “\#” (jogo da velha) e servem para filtrar assuntos que estão sendo comentado, a empresa assim pode monitorar o que está sendo falado da empresa. Sendo assim, Paine (2011 apud THOMAZ, 2014, p.88), "uma alternativa para monitorar conversas em mídias sociais em tempo real é a criação e utilização de hashtags para auxiliar na coleta e acompanhamento das referências ao evento ou assunto monitorado". Facebook, Instagram e Twitter são as ferramentas em que as hashtags são utilizadas em que as notícias podem ser monitoradas ao clicar na hashtag.

Tabela 5: Uso das hashtags

\begin{tabular}{lcc}
\hline Hashtags em quais redes sociais? & $\begin{array}{c}\text { Frequência } \\
\text { Absoluta }\end{array}$ & $\begin{array}{c}\text { Frequência } \\
\text { Relativa (\%) }\end{array}$ \\
\hline Facebook & 11 & $50,00 \%$ \\
Instagram & 7 & $31,82 \%$ \\
Twitter & 1 & $4,55 \%$ \\
Não possui & 3 & $13,64 \%$ \\
Total & $\mathbf{2 2}$ & $\mathbf{1 0 0 , 0 0 \%}$ \\
\hline
\end{tabular}

Fonte: Pesquisa Direta (2017). 
Outro elemento importante são as formas de comunicação utilizadas para divulgação (tabela 6) em que pode-se perceber o Facebook e Sites de internet com a mesma porcentagem $26,79 \%$, sendo seus principais meios de comunicação e divulgação para com seus clientes, logo em seguida vem o Instagram 17,86\% rede social de compartilhamento de foto e vídeos. Atualmente as redes sociais são importantes para atração e divulgação de destinos, serviços ou produtos, visto que as pessoas estão passando mais tempo conectados em seus equipamentos eletrônicos, na medida em que os consumidores compartilham suas experiências em suas redes sociais podem acabar influenciando outros usuários para conhecer o local. Segundo Sousa (2014, p.147) "atualmente é importante que qualquer destino turístico esteja presente, de qualquer forma, na web, sendo muitas das vezes a construção de um sítio na web o primeiro passo para tal”. Sendo assim, é importante as empresas possuírem perfil e utilizarem as redes para comunicação da empresa e promover seus serviços, além de ser uma forma de relacionamento e informações para os usuários.

Tabela 6: Formas de comunicação para divulgação

\begin{tabular}{lc}
\hline \multicolumn{1}{c}{ Formas de comunicação utilizadas para a divulgação } & Incidência \\
\hline Facebook & $26,79 \%$ \\
Instagram & $17,86 \%$ \\
Google + & $3,57 \%$ \\
Amigos/Família & $16,07 \%$ \\
Sites de Internet & $26,79 \%$ \\
Outros & $7,14 \%$ \\
Não possui & $1,79 \%$ \\
Total & $\mathbf{1 0 0 , 0 0 \%}$ \\
\hline
\end{tabular}

Fonte: Pesquisa Direta (2017).

\section{Análise dos formulários na internet}

Durante a averiguação na Internet, imersão na internet, por meio dos formulários podese observar nos sites das empresas que os links para redes sociais estão presentes em 92,3\%, os links mais recorrentes são Facebook e Instagram, no entanto alguns links para redes sociais como Pinterest, LinkedIn, Tumblr, Twitter e Google + também foram vistos. Observou-se ainda que além de links, alguns sites apresentavam integração com as redes sociais.

A rede social que apareceu integrada aos sites das empresas que compõem a amostra foi o Facebook no caso as Fanpages com a finalidade de atrair curtidas e seguidores, os plugins sociais do Facebook mais utilizados nos sites das empresas em questão foram os curtir e 
compartilhar a página e alguns ainda com o plug-in de visualização dos posts embutidos da Timeline da fanpage. Mais da metade $(53,8 \%)$ não apresentou quaisquer tipos de integração com Redes Sociais. Nesse sentido, Thomaz (2011, p.54) acrescenta que:

\begin{abstract}
As FanPages, são uma importante estratégia para o marketing de mídias sociais pois são utilizadas para disseminar informações sobre produtos e serviços, publicar promoções, estimular vendas, criar concursos, apresentar novidades e informações da organização ou destino turístico e promover conteúdo e integrar os usuários com as demais mídias e redes sociais que a organização ou marca está presente. THOMAZ, 2011, p.54)
\end{abstract}

Dessa forma foi possível observar que esta parte não atentou ainda para o poder que as ações feitas nos sites próprios e reproduzidas nas redes sociais têm na promoção da marca e consequentemente no impulsionamento das vendas. Analisou-se que apenas 46,2\% atentam para a importância de se ter sites mais convergentes e que buscam utilizar estratégias para isso.

Ao longo da pesquisa na Web por meios dos formulários estruturados observou-se que mais da metade $69,2 \%$ dos sites da amostra se faz uso de links para sites de reservas como Booking e TripAdvisor. Além disso, não somente a presença de links como também de integração destes sites de compras-reservas no próprio site da empresa, embora não tenha sido em quantidade considerável, 30,8\% faz uso desse tipo de permuta entre os sites, o que mais observou-se foi a integração do TripAdvisor despontando a nota geral das avaliações, as próprias avaliações e comentários dos visitantes, o que enriquece o site em conteúdo relevante para o potencial cliente. Desse modo, Gretzel e Yoo $(2008$, p. 6) em sua pesquisa sobre o impacto das reviews do TripAdvisor, apresentam que "A maioria dos leitores de revisão on-line procura opiniões de outros viajantes em sites de comunidade virtual $(92,3 \%)$, seguidos de sites de guia de viagem $(60,6 \%)$, agência de viagens on-line $(58,1 \%)$ e motores de busca ou portais (51,5\%)". Assim, de certo modo, evidencia-se o quanto é importante que as empresas de turismo estejam cadastradas nesse site.

As avaliações geram maior confiabilidade, pois é proveniente da opinião de quem já esteve no lugar e não dos responsáveis pela empresa, por isso as pessoas costumam buscar este tipo de informação nos sites, entretanto verificou-se que somente $7,7 \%$ dos sites analisados fazem uso das avaliações, os 92,3\% que não fazem, perdem por não terem essa base de dados observada como confiável, exemplo disso são os critérios que fazem parte do estilo de avaliação do TripAdvisor, que são parâmetros fundamentais para a determinação da nota da 
empresa no site, como o conforto, limpeza, localização, comodidades, funcionários e custobenefício que são fatores que os clientes levam em conta quando estão pesquisando onde ficar hospedado após a escolha do destino turístico.

$\mathrm{Na}$ coleta de dados pelos formulários observacionais, notou-se que as empresas não disponibilizam links para acesso a outras mídias como Instagram e TripAdvisor, em que 80\% das páginas dessas empresas ainda não disponibilizaram link para os aplicativos à página no Facebook, o que também se caracteriza como fator negativo pois com esta ferramenta existe um acrescimento de conteúdo significativo e importante para a página. De acordo com o próprio site do TripAdvisor instalar o aplicativo desse site de viagens para o Facebook é conseguir aproveitar o conteúdo existente como as avaliações dos viajantes, as pontuações, bem como as estatísticas de porcentagem recomendada, caso seja aplicável prêmios e ainda a foto principal e uma apresentação de slides de fotos do estabelecimento.

Outro fator relevante observado é se as empresas estão monitorando a página no Facebook para estarem atentas a perguntas que potencias clientes possam fazer como pode se observar nos comentários nas fotos perguntas relativos a valor da diária, descontos ou pacotes, que muitas dessas empresas não curtiam e nem respondiam quaisquer tipo de questionamento que favorece uma possível estadia ou elogios e críticas de quem já esteve hospedado no local, mesmo que sejam informações presentes nos sites próprios observou-se que muitas pessoas preferem saber por esse canal já que já estão ali buscando informações sobre o determinado estabelecimento e receber um feedback da empresa seria um ponto determinante na decisão de fechar um negócio. Para Marujo (2008, p.7), a internet criou um perfil de consumidores, um consumidor mais atento às informações para tomar uma escolha mais precisa de sua decisão, mais certo:

O advento da Internet fez com que surgisse um novo perfil de consumidor que, atualmente, está cada vez mais exposto a um conjunto de informações que influem determinantemente no processo da sua decisão, o que o torna mais seguro e exigente no ato de consumo.

Quanto ao uso dos sites Soares (2013, p.216) explica a importância da utilização do site, em que o site é o ambiente formal da empresa em que o cliente tem o contato, "atualmente as empresas utilizam as mídias sociais como meio de atendimento, aproximação com seu cliente e como ambiente de marketing direto. Mas o site ainda é o ambiente em que o cliente encontra as informações e fecha negócios, inclusive". 
Com relação às fotografias de infraestrutura, gastronomia, paisagem e dos hóspedes outro tipo de objetos principais em questão são as paisagens, buscou-se saber se estas empresas fazem uso de imagens das paisagens do município de Parnaíba como forma de estimular e atrair turistas para a região. Observou-se que $36 \%$ das empresas publicam fotos de infraestrutura, fotos de gastronomia em $68 \%$ das fanpages, fotos de paisagem tem frequência de $52 \%$ dos posts das empresas e fotos de clientes $48 \%$ nas redes sociais. Suas fotografias publicadas foram analisadas com critério de atualização nos últimos 30 dias, entretanto observou que dentre estas empresas algumas não costumam alimentar a fanpage há pelo menos 11 meses. Essa mídia vai transmitir a mensagem desejada do lugar para o potencial turista de qualquer segmento, seja ele turismo de negócios, de lazer, de aventura, entre outros. Por isso precisa-se ter o cuidado de como vai ser passado essa imagem do destino para o turista. Para Caldeira et al. (2004, p.6):

É necessário salientar também a importância do cuidado da mídia no planejamento turístico do local. Somente com a conscientização de que precisamos trabalhar melhor com as imagens para que seja absorvida de forma que se preserve a identidade e a cultura da cidade visitada sem pensar somente na lucratividade desse segmento.

Por outro lado, observou-se que as empresas que costumam usar as hashtags foram empresas que também tinham feito alguma atualização de fotos da Timeline em menos de $24 \mathrm{~h}$ demonstrando assim bom gerenciamento dessa ferramenta e atualização frequente de imagens e conteúdo. Percebeu-se também que $23,1 \%$ dos sites da amostra apresenta vídeos, destes, observou-se menos de dois vídeos por site, observou-se ainda que são vídeos curtos, antigos e institucionais.

Em relação aos tipos de objetos principais focalizados nas imagens fotográficas no Instagram observou-se que a Infraestrutura aparece em apenas 40\% das imagens, sendo ainda este tipo mais recorrente nas empresas do segmento de meios de hospedagem. Em relação a paisagens observou-se que $90 \%$ costumam retratar paisagens dos destinos comercializados, por exemplo, destinos na Rota das Emoções para as agências e operadoras de turismo e para empresas de meios de hospedagem, paisagens dos atrativos de Parnaíba como o Delta. Sobre as imagens de Gastronomia, ambos os seguimentos apresentaram poucas, caracterizando um total de $20 \%$. Ainda sobre o Instagram, nessa rede social é mais comum a presença de imagens de hóspedes, observou-se que $60 \%$ das empresas costuma publicar fotos de hóspedes e ainda 
estimular os usuários a compartilharem conteúdo como a técnica do Repost. De acordo com o site Buffer Social (2017) "No Twitter, você pode retweetar. No Facebook, existe a opção de compartilhar uma postagem. E no Instagram, você pode repost, o que é essencialmente uma maneira de compartilhar uma imagem de outro usuário do Instagram com seus seguidores." Das empresas analisadas $40 \%$ desfrutam dessa técnica.

Segundo uma pesquisa realizada pelo Paypal e Bigdatecorp (2016) para o Perfil do Ecommerce Brasileiro sobre o comércio eletrônico no país. "Dados interessantes é que 60,71\% dos sites de comércio eletrônico brasileiros usam as redes sociais para turbinar vendas e promoções. Sendo o Facebook o preferido, com 54,96\%. Em seguida vêm Twitter, com 35,87\%; YouTube, 20,80\%; e Instagram, 9,32\%”. Esses dados mostram o quanto as redes sociais têm ajudado na divulgação e assim influenciando um número maior de pessoas, já que as redes sociais alcançam um público maior. "A pesquisa ainda mostra que em 2015 os sites de e-commerce representavam 2,65\% do total de sites brasileiros, esse número cresceu para 3,54\% em 2016, sendo um aumento de 21,52\%". Com esses dados percebe-se o quanto o Ecommerce tem crescido e a necessidades de as empresas investirem no comercio eletrônico. Sendo assim, a maior parte das empresas analisadas não exploram satisfatoriamente os meios de comunicação/divulgação, já que não atualizam seus meios de comunicação com frequência e não costumam interagir frequentemente com os usuários. As empresas até possuem o perfil na rede social, entretanto não fazem o uso que é preciso das redes, isso se dá pelo fato de a maioria das empresas não possuírem um gestor da área de marketing ou comunicação e pela falta de um plano de marketing. Segundo Da Silva Costa e Perinotto (2017, p.21) "Algumas agências contratam uma empresa específica para fazerem as publicações no Instagram como as agências A e P. Já as outras agências B, C, D, E, F, J, M, e Q não possuem uma pessoa específica". Nessa pesquisa que foi estudado o uso do Instagram nas agências de Parnaíba foi percebido que apenas duas empresas contrataram profissionais da área para divulgação, provando que a maioria das empresas não possui profissionais que trabalham a divulgação.

Com os resultados obtidos pode-se investigar como as empresas estão utilizando os meios de comunicação para divulgação e atração de turistas para a localidade, o município de Parnaíba, sendo este o objetivo da pesquisa, através de questionários respondidos pela visão do empresário e análise feita na internet do uso dos meios de comunicação, apesar das empresas afirmarem estarem presente nas Redes Sociais como Facebook (31,67\%), Sites $(28,33 \%)$ e 
Instagram (23,33\%), observou-se através dos formulários online que algumas empresas passam longos períodos sem realizar publicação, se o perfil não é atualizado não é possível atrair pessoas para o local ou comprar o serviço, também foi detectado com a pesquisa nas próprias redes sociais e sites que 52\% não utiliza hashtags e só $10 \%$ publica vídeos nas redes sociais, demonstrando pouco uso das ferramentas como forma de atrair mais clientes e propagação da empresa.

Através dos dados obtidos da pesquisa de campo e pelos formulários online identificouse que são poucas as empresas que fazem uso das ferramentas de comunicação, sabendo que a maioria afirma que possuem perfil, mas são poucas as empresas que atualizam com frequência seus meios de comunicação. Para tanto, Da Silva Costa e Perinotto (2017, p.20) afirmam em sua pesquisa que "das 16 agências cadastradas no CADASTUR, apenas nove estavam no Instagram, sendo que, uma desde 2015 não publica nada". Desse modo acredita-se que as empresas não fazem o uso devido dessas ferramentas, pois a maioria das empresas é familiar e não possuem pessoal formado na área de marketing ou comunicação, conforme o levantamento realizado do perfil das empresas de turismo em Parnaíba-PI.

No monitoramento dos meios de comunicação na internet pode-se perceber que são poucas as postagens sobre o município de Parnaíba, é mais frequente fotos da infraestrutura da empresa e de outras localidades. Como ressaltam Da Silva Costa e Perinotto (2017, p.20) “As empresas poderiam dispor mais informações e imagens da cidade alavancando mais o turismo local, já que é uma cidade com grande potencial turístico e histórico, além de tudo, possui grandes museus e casarões antigos." Sabendo que para o turismo a imagem é importante para divulgação do turismo local se faz relevante o uso mais adequado da internet e redes sociais para um alcance maior de usuários que poderão vir a tornarem-se clientes e turistas para Parnaíba.

\section{CONSIDERAÇÕES FINAIS}

Este trabalho teve o intuito de investigar quais os meios de comunicação utilizados pelas empresas de agenciamento e meios de hospedagem do município de Parnaíba-Piauí, com cadastro no Cadastur, quais as ferramentas de mídias utilizadas para divulgação de seus atrativos e atração de turista ao local. As leituras sobre comunicação turísticas, mídias sociais, internet, imagens, fichamento das leituras, elaboração do questionário, contribuíram para embasamento teórico para análise sobre a comunicação turística de Parnaíba-Piauí. 
A partir da análise dos dados da pesquisa e estudos sobre o assunto considera-se que a tecnologia de comunicação é utilizada, porém não de forma efetiva em todas as empresas da amostra, no entanto constatou-se crescimento do uso do marketing digital, sendo o Facebook a principal mídia social utilizada, seguido do Site e Instagram, percebeu-se também que todas as empresas estão cadastradas em pelo menos um ou mais sites de viagens. Através dessa pesquisa verificou-se que estas são as principais mídias utilizadas pelos empreendedores turísticos em Parnaíba/Piauí. Pode-se perceber que a maioria das empresas utilizam conteúdo gerado pelo usuário, por meio de fotografias e hashtags, o CGU é importante para que outras pessoas vejam experiências, comentários sobre determinado local ou empresa. Os resultados demonstraram que ainda é preciso saber comunicar as imagens e informações pertinentes aos pontos turísticos que a cidade tem a oferecer.

Constatou-se ainda que as empresas não se utilizam de todas as funções que os sites e mídias sociais tem a oferecer, tendo em vista que os segmentos analisados foram os meios de hospedagem e agências e operadoras de Turismo, constatou-se comportamentos diferentes da presença dessas empresas nas redes sociais. Em relação ao vínculo com sites de viagens nesta rede social se faz pouco presente, diferente do Facebook em que foi possível observar diferentes formas de integração, seja por meio de avaliações, comentários ou plug-ins para curtir e compartilhar, no Instagram este quesito é mais restrito até mesmo pelas interfaces diferentes dos aplicativos e pelo tipo de conteúdo adaptado as especificidades de cada um.

Portanto, foi percebido que as empresas do município de Parnaíba-Piauí utilizam as TICs como principal meio de divulgação e promoção de seus produtos e serviços, as empresas ainda utilizam fotografia de paisagem, infraestrutura e gastronomia para promoção do local e do empreendimento, mas de forma incipiente. Entretanto ainda é preciso desenvolver melhor seus usos das tecnologias de comunicação, pois como foi mostrado algumas empresas não atualizam seus meios digitais com frequência, contudo, foi constatado também que algumas empresas trabalham as mídias sociais com êxito, fazendo uso de cada ferramenta oferecida pela plataforma como um meio de divulgar seu trabalho, sendo assim é relevante que as empresas busquem trabalhar com pessoas especializadas na área, atualizem suas redes sociais com frequência, fazendo o uso das hashtags e outros recursos para localização e divulgação de imagens e consequentemente dos endereços eletrônicos dessas empresas, ou seja, que se faça o uso de estratégias de marketing digital regularmente para promover a empresa e o destino e 
com isso tentem fidelizar os clientes e atrair novos consumidores. Espera-se que a pesquisa sirva como base para pesquisas futuras sobre o uso das tecnologias de comunicação nas agências e meios de hospedagem de Parnaíba ou ainda outros destinos turísticos.

\section{REFERÊNCIAS}

ARRUDA, Eucidio; PIMENTA, Durcelina. Algumas reflexões sobre a internet e as estratégias comunicativas no marketing em turismo. Caderno Virtual de Turismo, v. 5, n. 4, 2005.

BAPTISTA, Sofia Galvão; CUNHA, Murilo Bastos da. Estudo de usuários: visão global dos métodos de coleta de dados. 2007.

BATTISTI, Iara Denise Endruweit; BATTISTI, Gerson. Métodos Estatísticos. Rio Grande do Sul: Ijuí: Ed. Unijuí, 2008. - 80 p. - (Coleção educação à distância. Série livro-texto)

BIGDATECORP. Perfil do E-Commerce Brasileiro. (2016) Disponível em: < https://www.ecommercebrasil.com.br/noticias/paypal-detalha-perfil-do-e-commerce-brasileiro2016/> Acesso em 10 de janeiro de 2017. BRASIL

BORGES, Marta. 7 Tendências para quem deseja empreender no setor de turismo. São Paulo, mar. 2016. Disponível em <http://revistapegn.globo.com/Banco-de-ideias/Diversao-eturismo/noticia/2016/03/7-tendencias-para-quem-deseja-empreender-no-setor-de-turismo.html> Acesso em: jun. de 2016.

BORGES, Marta. 8 ferramentas de Marketing Digital Essenciais para o Turismo. São Paulo, mai. 2016. Dísponivel em: <http://agentenoturismo.com.br/8-ferramentas-essenciais-demarketing-digital-para-o-turismo/>. Acesso em: mai de 2017.

BORGES, Marta. Facebook para Empresas e Destinos Turísticos. São Paulo, mai. 2012. Disponível em: <http://agentenoturismo.com.br/facebook-para-empresas-e-destinosturisticos/>. Acesso em: junho de 2016.

BORGES, Marta. Vídeos como estratégia de marketing digital para Turismo. São Paulo, set. 2016Dísponivel em: <http://agentenoturismo.com.br/2016/09/13/videos-marketing-digitalturismo/>. Acesso em: dez. 2017.

BRASIL. Segmentação do turismo e o mercado. Brasília: Ministério do Turismo, 2010.

BUFFER SOCIAL. Introducing Instagram Reposting by Buffer: Never Run Out of Amazing Content. Out. 2016. Dísponivel em: <https://blog.bufferapp.com/how-to-repost-oninstagram>. Acesso em: ago. 2017.

CALDEIRA, Letícia Rocha. Et al. A Mídia no Turismo. [S.I.: s.n.], 2004.

CERVO, A. L. BERVIAN, P. A. Metodologia científica. 5.ed. São Paulo: Prentice Hall, 2002.

COBRA, Marcos. Administração de Marketing. 3 ed. Rio de Janeiro: Elsevier. 2009

CRUZ, Vera Lúcia Lima da; MOTA, Karol Monteiro; BARBOSA, Vânia Soares; PERINOTTO, André Riani Costa. Redes sociais como estratégia de marketing turístico: o Facebook e a região norte do Estado do Piauí-Brasil. Revista de Investigación em Turismo e Desarollo Local, Malaga, v. 5, n. 13, p. 2012, 2012. 
DA SILVA COSTA, Rodrigo; PERINOTTO, André Riani Costa. O Uso do Instagram por Agências de Turismo do Município de Parnaíba/PI. Ateliê do Turismo, v. 1, n. 1, 2017.

DA SILVA FLORES, Luiz Carlos; DE SENA CAVALCANTE, Leila; LEAL RAYE, Roberta. Marketing turístico: Estudo sobre o uso da tecnologia da informação e comunicação nas agências de viagens e turismo de Balneário Camboriú (SC, Brasil). Revista Brasileira de Pesquisa em Turismo, v. 6, n. 3, 2012.

DA SILVA, Danilo Serafim; MENDES-FILHO, Luiz. Uma análise preliminar do uso de comentários na internet na escolha de um destino de viagem. Revista Turismo: estudos e práticas, v. 2, n. 2, 2014.

DE ANDRADE, Mariana Bueno et al. Busca Por Informações E Imagem De Destinos Turísticos: Análise Dos Estímulos Ofertados Nos Websites De Órgãos Governamentais De Turismo Dos Principais Estados Do Nordeste Brasileiro. Turismo y Desarrollo Local, n. 13, 2012.

DE SENA JARDIM, Gabriel; SANT'ANNA, Adriano Lins Pinheiro. Turismo on-line: oportunidades e desafios em um novo cenário profissional. Revista Acadêmica Observatório de Inovação do Turismo, v. 2, n. 3, 2007.

DE SOUZA, Anderson Gomes; KOVACS, Michelle Helena. Marketing turístico e promoção: uma análise sobre as ações de comunicação empreendidas pela empresa de turismo de Pernambuco. Turismo-Visão e Ação, v. 11, n. 2, p. 201-217, 2009.

GRETZEL, Ulrike; YOO, Kyung Hyan. Use and impact of online travel reviews. Information and communication technologies in tourism 2008, p. 35-46, 2008.

IBGE. Instituto Brasileiro de Geografia Estatística. Censo Populacional. Parnaíba-PI. 2016. Disponível em: <http://www.ibge.gov.br> Acesso em: out. 2017.

KOTLER, Philip; KELLER, Kevin Lane. Administração de marketing. 12. ed. São Paulo: Pearson Prentice Hall, 2006.

LAKATOS, Eva Maria; DE ANDRADE MARCONI, Marina. Técnicas de pesquisa: planejamento e execução de pesquisas, amostragens e técnicas de pesquisas, elaboração, análise e interpretação de dados. 3.ed. São Paulo: Atlas, 1996.

LEUNG, Daniel et al. Social media in tourism and hospitality: A literature review. Journal of Travel \& Tourism Marketing, v. 30, n. 1-2, p. 3-22, 2013.

MARUJO, Noémi. A internet como novo meio de comunicação para os destinos Turísticos: O caso da Ilha da Madeira. Revista Turismo em Análise. v. 19, n. 1, 2008.

PARNAÍBA. Portal da Prefeitura Municipal de. Dados Gerais. Parnaíba-PI. Disponível em: < http://www.parnaiba.pi.gov.br/>. Acesso em: 16 de junho 2016.

PERINOTTO, André Riani Costa. Investigando a comunicação turística de Parnaíba/PI-Brasil: internet e redes sociais, descrição e análise. TURyDES, v. 6, n. 15, 2013.

PIAUÍ, Secretaria Estadual de Turismo - SETUR. Pólo Costa do Delta. Piauí. Disponível em: < http://www.turismo.pi.gov.br/pt-br/municipios/parnaiba>. Acesso em: 16 junho 2015. 
RUSCHMANN, Doris Van de Meene. Marketing turístico: um enfoque promocional. Papirus. 1990

SOARES, Cláudia Mesquita Pinto. Hospitalidade virtual: uma tentativa de compreensão. Revista Hospitalidade, n. 2, 2013.

SOUSA, Carina. A influência da internet na escolha de um destino turístico. Cogitur, Journal of Tourism Studies, n. 5, 2014.

THOMAZ, Guilherme Mendes. Inovação da promoção turística online do Estado do Paraná. Universidade Federal do Paraná, 229. 2011

THOMAZ, Guilherme Mendes. Processo de mineração de conteúdos em mídias sociais para auxílio na gestão de destinos turísticos. Dissertação (mestrado em Turismo), Universidade Federal do Paraná, Paraná. 2014.

TOMIKAWA, Jun Matsuoka. A importância da imagem no processo de escolha da destinação turística. 71f. Trabalho de conclusão (Curso de Especialização em Gestão e Marketing do Turismo V) - Centro de Excelência em Turismo, Universidade de Brasília - UnB, Brasília. 2004.

XIANG, Zheng; GRETZEL, Ulrike. Role of social media in online travel information search. Tourism management, v. 31, n. 2, p. 179-188, 2010.

Artigo recebido em: 02/04/2018

Avaliado em: 17/05/2018

Aprovado em: 23/05/2018 